Acta Technologica Agriculturae 3

Nitra, Slovaca Universitas Agriculturae Nitriae, 2021, pp. 103-111

\title{
DYNAMIC MODELLING AND MOTION CONTROL OF A 4-DOF SCARA ROBOTIC ARM FOR VARIOUS FARM APPLICATIONS
}

\author{
Ali ROSHANIANFARD ${ }^{*}$, Du MENGMENG ${ }^{2}$, Samira NEMATZADEH ${ }^{1}$ \\ ${ }^{1}$ University of Mohaghegh Ardabili, Iran \\ ${ }^{2}$ Henan University of Science and Technology, Luoyang, Henan, China
}

\begin{abstract}
Agriculture as a key industry for human food suply will face various concerns in near future. This research is complementary and aims to present the dynamic modelling and simulation, as well as algorithm development of a 4-DOF SCARA-type robotic arm designed for real agricultural cultivation process, such as seeding, watering, fertilizing, weeding, etc. In terms of a previously designed system, the equations of motion profile were solved (acceleration and deceleration control of joints) to reduce inertia, ensure a smooth motion, and minimize torque requirement. The algorithm is evaluated by PTP motion, TCP linear motion, and spline motion. The results show that the developed algorithm can move the TCP using ST-profile. Furthermore, it can control all joints for an estimated time duration. A novel method was developed to manoeuvre the TCP along the shortest path to reach a goal point. Finally, the algorithm was evaluated in a closed path inside the working space.
\end{abstract}

Keywords: smart; robot; algorithm; dynamics; kinematics

In the near future, the world will not have enough food to service. The expanding population will reach nearly 9.7 billion people in 2050, and farmers should double their farm outputs (FAO, 2017). People waste a third of their food (Bravi et al., 2019); natural disasters, global warming, and climate change influence farms (Singh and Singh, 2017); labour shortage, farmer aging, and income issues pose risks for farm work (Marinoudi et al., 2019). Apart from these, human mistakes, uncertain future of farming, limited arable land, and soil erosion are noteworthy.

Digital farming (DF) has many solutions for the mentioned concerns thanks to so many valuable studies, such as the social science on smart agriculture (Klerkx et al., 2019), digital innovation in smart farming (Ayre et al., 2019), and DF and ICT (Shibusawa, 2018). Multiple researches developed new robots for cultivation of crops, such as apple (Lv et al., 2019), orange (Garner et al., 2006), tomato (Li et al., 2019), strawberry (Khosro Anjom and Vougioukas, 2019; Aliasgarian et al., 2015), kiwifruit (Williams et al., 2019), grape (Luo et al., 2018), heavy-weight crops (Roshanianfard et al., 2018; Kamata et al., 2018; Roshanianfard and Noguchi, 2017, 2018b; Roshanianfard, 2018), and pumpkin (Roshanianfard and Noguchi, 2016, 2018a; Roshanianfard et al. 2020, 2021). Certain researchers applied smart systems on commercialized platforms, such as tractors (Wang and Noguchi, 2019), combines (Zhang et al., 2013), boats (Liu et al., 2017), all-terrain-vehicles, utility vehicles (Cviklovič et al., 2016), drones (Kashkarov et al., 2018), and drones for digital farming applications (Roshanianfard et al., 2019).

The manipulation unit plays a significant role in farmrobot operation. Previously developed arms are mostly installed on a prototype platform with numerous limitations under real farm conditions. Moreover, the development of robotic arms for commercialized platforms still requires extensive research. Most of the commercialized robotic arms were not developed for agricultural environments, which tends to be dusty, dirty, and humid; therefore, for appropriate operation, they require indoor and isolated rooms.

In this regard, development of a specifically designed robotic arm, which is to be installed on the autonomous tractors working in the real agricultural field, is a new area (Roshanianfard et al., 2021). The objective of this research is to design a robotic arm that can handle unpredictable farm situations, such as rain, wind, dust, mud, and vibration with an optimized number of degrees of freedom (DOF). Therefore, it can be concluded that the novelty of designed robotic arm is in:

1. its adaptability to use under real agricultural farm conditions due to its specifically designed components (joints, links, and controlling unit), which are not affected by vibration, dust, and humidity;

2. specifically simplified quick algorithm to collaborate with an autonomous tractor with minimum delay;

3. its sufficient payload per weight compared with industrial robotic arms (Roshanianfard et al., 2021).

Finally, the objectives of this research are the development of joints' motion profile with efficient equations, and performance simulation based on different possible motion scenarios. 


\section{Material and methods}

\section{Designed system}

The system is a 4-DOF SCARA type robotic arm presented by Roshanianfard et al. (2021) (Fig. 1). It is equipped with a linear screw to move in Z-direction. The aluminium (AL5052) was selected for the body due to its low density and good weld-ability. The structure was designed for $20 \mathrm{~kg}$ of payload and 1.5 of factor of safety (FOS). It has 4 joints: $J_{1}$, $J_{2}, J_{3}$, and $J_{4}$. The $J_{1}$ is connected to a long screw and moves the tool centre point (TCP) in Z-axis. The $J_{2}$ and $J_{3}$ move the rear arm and forearm, respectively, in $\mathrm{X}$ - and Y-directions. The $J_{4}$ is for rotating end-effector (EE). The robotic arm (RA) can smoothly manoeuvre in a 3D environment and is designed to do agriculture farm works (seeding, watering, fertilizing, weeding, harvesting, etc.). The coordination of joints and home coordination was set based on the righthanded coordinate system (Fig. 1). The rotations in the $X-$, $Y-$, and Z- direction are named roll $\left(r_{x}\right)$, pitch $\left(r_{y}\right)$, and yaw $\left(r_{z}\right)$, respectively.

\section{Dynamics of robot}

\section{Motion profile}

In this section, the dynamic motion profile of joints is presented, because the RA control position based on an optimized profile reduces the acceleration, deceleration, and potential damage to joints. It manages the controlling at the start and stop point and provides a smooth path in point-to-point (PTP) motion (to move the distance between two points - point-to-point motion). By sending a command in a certain time cycle, adjusting the position, velocity, and acceleration, the robot tractor (RT) motion between points can be controlled without backlash. Otherwise, the inertia due to fast acceleration and deceleration can damage components and result in rapid and inappropriate motions. The maximum velocity and maximum acceleration limitation must be defined during controlling in order to protect the servo motors from huge backlash and inertia. In this section, the inputs should include target position, target velocity, maximum velocity, and target acceleration. The outputs should be recorded as position, velocity, acceleration, and jerk on each time cycle. The joint motion is divided into 3 segments: acceleration, constant velocity, and deceleration. Velocity and acceleration functions were calculated for each segment, and several methods, including an S-shaped profile, asymmetric motion profile, and trapezoidal profile, were applied. After multiple calculations, a novel ST-shaped profile was developed (Fig. 2). This profile is divided into 3 segments:

1. acceleration segment,

2. zero acceleration/constant velocity,

3. deceleration segment.
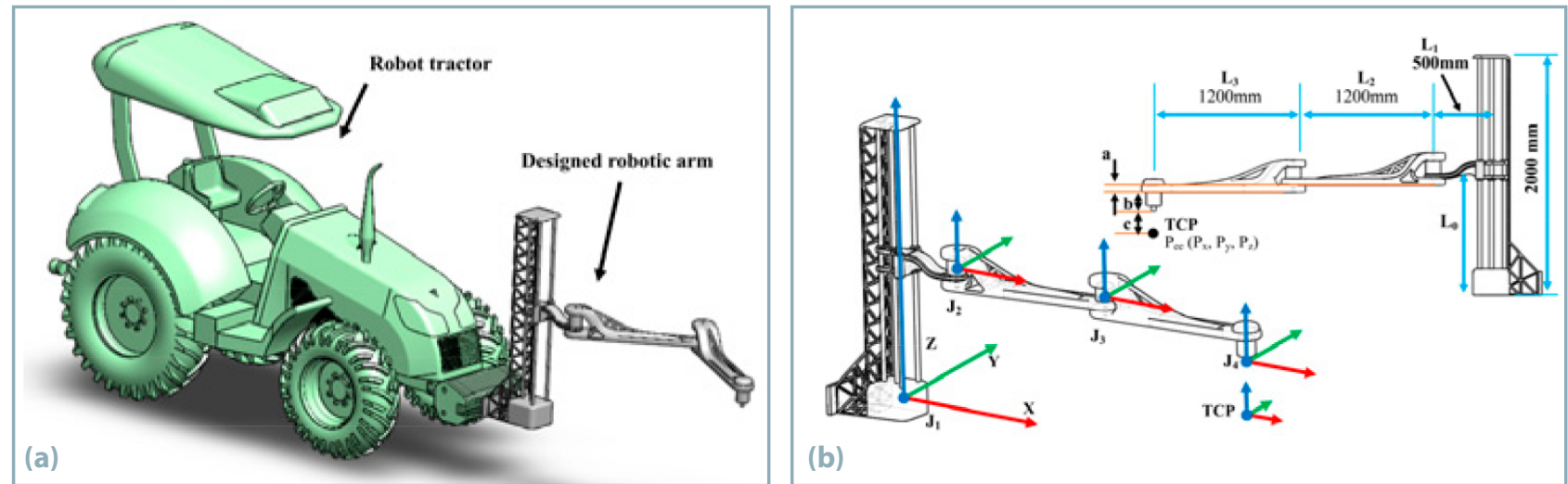

Fig. 1 (a) Designed robotic arm for farm use and (b) its applied coordination

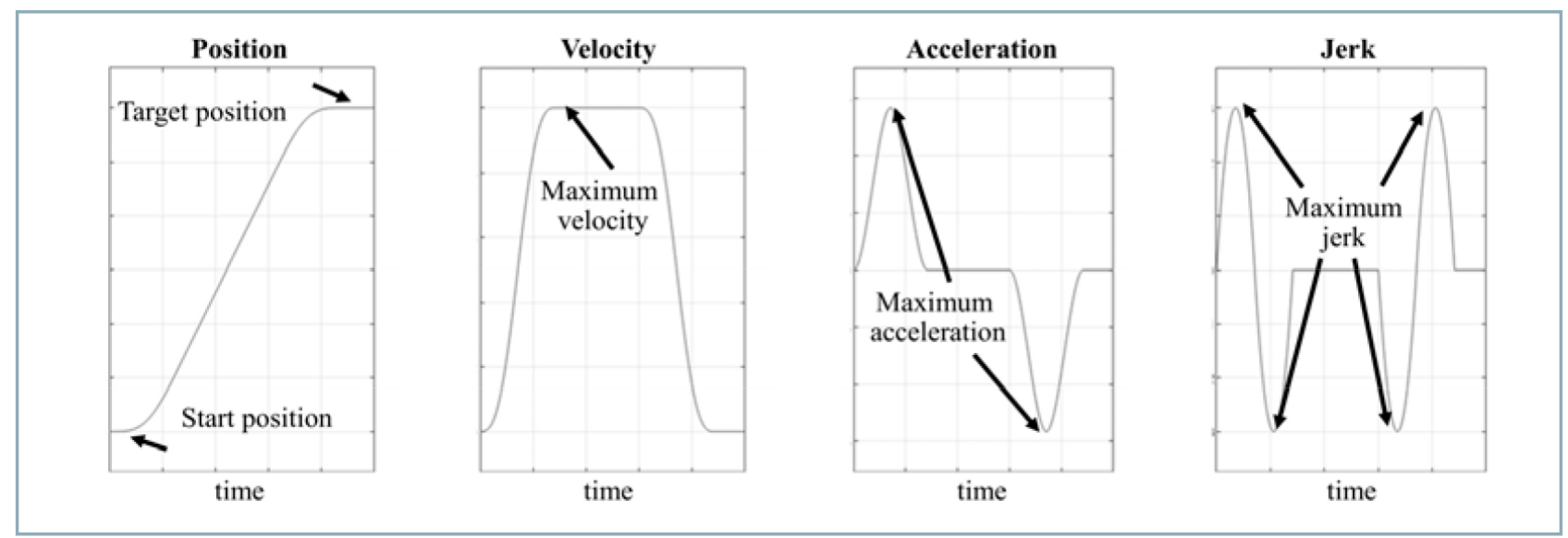

Fig. 2 Position, velocity, acceleration, and jerk profile of ST-shaped profile 
In segment 1, the joint velocity increased using Eq. 1, and the acceleration was bell-shaped (Eq. 2). During segment 2 , the velocity was constant, and acceleration was zero. In segment 3, the joint velocity decreased using Eq. 4, and the acceleration showed a bell-shaped behaviour (Eq. 5). The time duration of segment 1 , segment 2 and segment 3 was $\left(0, t_{1}\right),\left(t_{1}, t_{2}\right)$, and $\left(t_{2}, t_{3}\right)$, respectively. The acceleration and deceleration times were considered to be the same.

After several experiments, the equations of an optimized motion profile with a controllable maximum acceleration and velocity were calculated. The acceleration and deceleration for segment 1 was calculated as follows:

$$
\begin{array}{cc}
V_{\text {acc }}=V_{\max } \frac{1}{1+e^{-t+10}} & 0 \leq t \leq t_{1} \\
a_{a c c}=4 a_{\max } \frac{e^{-t+10}}{\left(e^{-t+10}+1\right)^{2}} & 0 \leq t \leq t_{1}
\end{array}
$$

where:

$V_{\text {acc }}$ - joint acceleration velocity; $V_{\max }$ - maximum limited velocity of joint; $t$ - time; $t_{1}$ - time at the end of acceleration segment; $a_{a c c}$ - joint acceleration; $a_{\max }$ - maximum limited acceleration of joint

The plots are shown in Fig. 3.

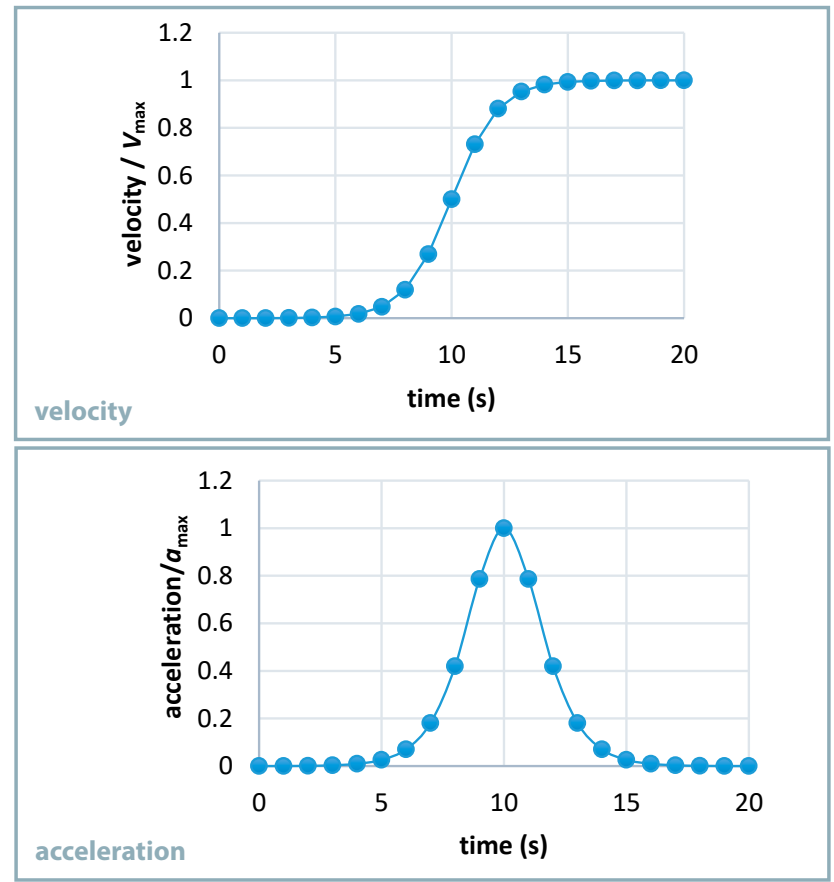

Fig. 3 Profile illustration for segment 1

For segment 2, the acceleration is zero and the velocity equals to $V_{\max }$ :

$$
V_{\text {acc }}=V_{\max } t_{1} \leq t \leq t_{2}
$$

For segment 3, the acceleration and deceleration come from the following equations:

$$
V_{\text {dec }}=V_{\max } \frac{1}{1+e^{t-10}} \quad t_{1} \leq t \leq t_{3}
$$

$$
a_{\text {decc }}=-4 a_{\max } \frac{e^{t-10}}{\left(e^{t-10}+1\right)^{2}} \quad t_{1} \leq t \leq t_{3}
$$

where:

$V_{\text {dec }}$ - joint deceleration velocity; $t_{3}$ - total motion time; $a_{d e c}-$ deceleration acceleration of joint

The plots are shown in Fig. 4.
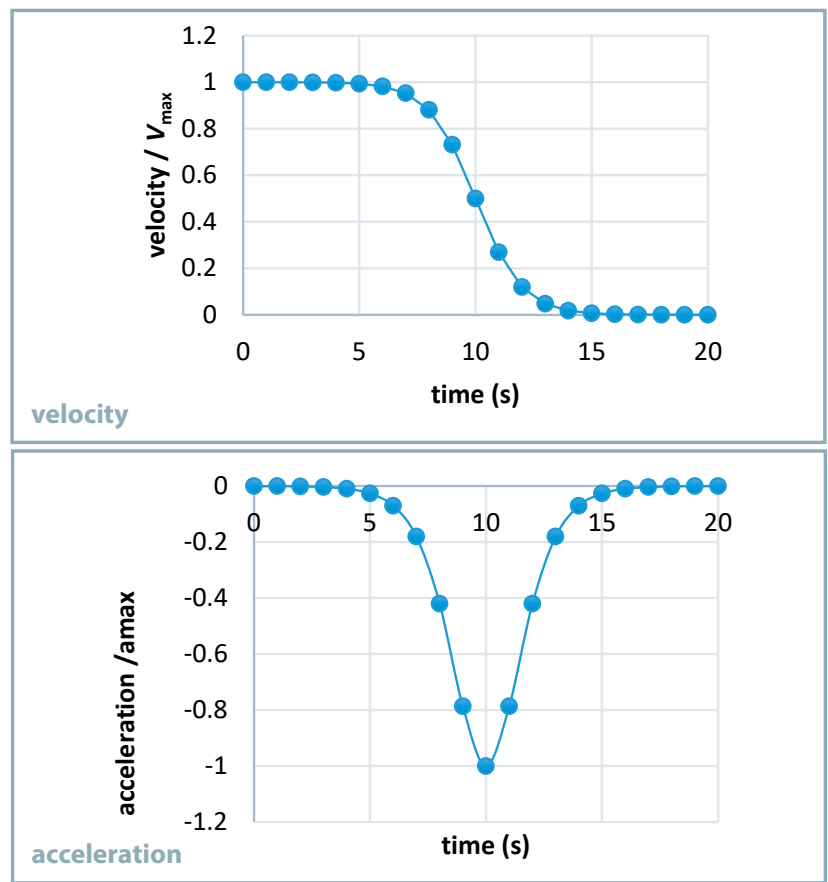

Fig. 4 Profile illustration for segment 3

Finally, a full profile during a motion resulted, as shown in Fig. 5.

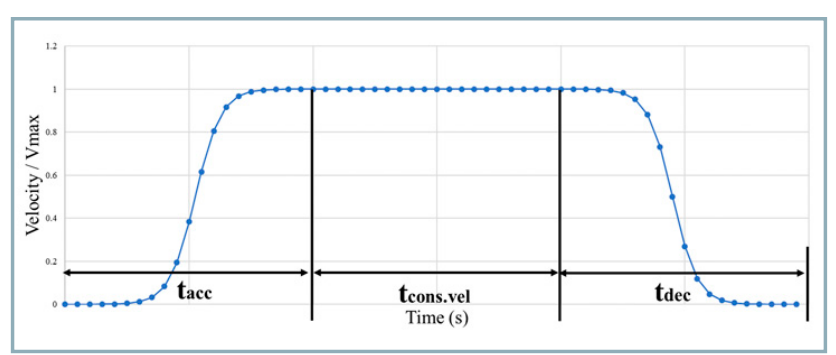

Fig. 5 Full velocity profile

\section{Parameters integration}

To code the mentioned equations and find appropriated $t_{1}$ and $t_{2}$ based on the limited maximum velocity, the following calculations are required. During the motion between two positions, the distance between two points is equal to the integral of velocity profiles as:

$$
\begin{gathered}
P_{\text {end }}-P_{\text {start }}=\int_{0}^{t_{1}} V_{\max } \frac{1}{1+e^{-t+10}} d t+\int_{t_{1}}^{t_{2}} V_{\max }\left(t_{2}-t_{1}\right) d t+ \\
\int_{t_{2}}^{t_{3}} V_{\max } \frac{1}{1+e^{t-10}} d t \rightarrow
\end{gathered}
$$




$$
\begin{gathered}
\frac{P_{\text {end }}-P_{\text {start }}}{V_{\max }}=\int_{0}^{t_{1}} \frac{1}{1+e^{-t+10}} d t+\int_{t_{1}}^{t_{2}}\left(t_{2}-t_{1}\right) d t+ \\
\int_{t_{2}}^{t_{3}} V_{\max } \frac{1}{1+e^{t-10}} d t \rightarrow
\end{gathered}
$$

Approximate function:

$$
\begin{gathered}
\frac{P_{\text {end }}-P_{\text {start }}}{V_{\max }}=\log (22026.5)+\log (2.72)^{t_{1}}+\left(t_{2}-t_{1}\right)+ \\
\quad\left(\left(t_{3}-t_{2}\right)-\log (22026.5)-\log (2.72)^{t_{3}-t_{2}}\right)
\end{gathered}
$$

Based on the calculation, there is:

$$
\frac{P_{\text {end }}-P_{\text {start }}}{V_{\max }}=t_{2}
$$

If supposed that $t_{a c c}=t_{d e c}$, then:

$$
t_{3}=2 \cdot t_{\text {acc }}+t_{\text {cons. vel }}
$$

Then:

$$
\begin{gathered}
t_{\text {acc }}=t_{\text {dec }}=t_{3}-t_{2} \\
t_{2}=t_{\text {acc }}+t_{\text {cons.vel }}=\frac{P_{\text {end }}-P_{\text {start }}}{V_{\max }}
\end{gathered}
$$

where:

$P_{\text {end }}$ - final position; $P_{\text {start }}$ - start position; $t_{\text {acc }}$ - acceleration time $\left(t_{1}-t_{0}\right) ; t_{\text {dec }}-$ deceleration time $\left(t_{3}-t_{2}\right) ; t_{\text {cons. vel }}$ - time duration with constant velocity $\left(t_{2}-t_{1}\right)$

When the $V_{\max }$ is set for a motion, the $t_{2}$ and $t_{3}$ can be automatically calculated from Eqs 9 and 10, respectively. Those equations help to find an optimum period for acceleration, deceleration, and maximum velocity to move between two points. This equation should be applied in each direction (X, Y, and Z).

\section{Motion tests}

The controlling program of this task was coded in Visual C++ with related APIs, libraries, and calculated equations in the previous section. To verify equations and methodologies, the motions were tested based on three scenarios: PTP motion, TCP motion, and spline motion.

\section{PTP motion}

In PTP motion, a user sets $P_{\text {start }}$ and $P_{\text {end }}$ and the rotation tool (RT) moves between the point without consideration of the path linearity. When this command triggers in each period $(0.1 \mathrm{~s})$, each joint starts moving and joints' motion follows the calculated profiles. Each joint moves at the same time. Certain joints might not be needed to move. The tool offset can be taken into consideration. The inputs of this test were the $P_{\text {start }}, P_{\text {endr }}$ and $t$. The outputs should be the joints' positions, velocity, and acceleration. When the time duration over-errored the velocity, the velocity was limited. This will be used when the RA tries to perform harvesting or watering, in which the path linearity is not a priority.

\section{TCP linear motion}

In this scenario, a user sets $P_{\text {start }}$ and $P_{\text {end }}$ for EE and the TCP moves along the shortest path and follows the calculated profile. In this test, the tool offset can be ignored. The inputs should be the $P_{\text {start }} P_{\text {endr }}$ and $t$. The outputs are TCP's positions, velocity, and acceleration. If the time duration makes velocity over error, the velocity was limited. This motion helps the RA to move along the shortest path when it has time limitations or when it wants to increase the task speed.

\section{Spline motion}

In this scenario, the robot must be able to move on a predetermined path such as a square, a circle, or an unidentified path on a surface. The program recognizes the possibility of motion, checks the entire shape in order to ensure that all points are inside the working space. After all, it selects the best strategy to move. This motion is designed to move on a flat surface when the RA sprays, waters, or fertilizes crops. In this scenario, the RA does not need to move up or down ( $\mathrm{Pz}$ is constant). There are certain points on the ground and the RA moves smoothly; appointing each point to follow a curve. At the same time, TCP's motion controls the smooth variation of velocity and acceleration.

\section{Results and discussion}

\section{Motion profile}

Based on the calculated equations, the motion of each joint was controllable based on the predetermined $P_{\text {start }}$ $P_{\text {end }}$ and $V_{\max }$. As shown in Fig. 6, each joint moved based on the ST-shaped profile equations. This motion decreased the value of backlash applied on the servo motors and reduces the vibration of operations due to the optimized profile set for acceleration and deceleration. In this task, the acceleration and deceleration times were set as $20 \%$ of the total motion time duration, but it can be changed for different tasks, speeds, and missions. The traveling time was set constant for all joints and is dependent on the distance and maximum $V_{\max }$ limitation in a $3 D$ environment. Fig. 6 shows results of the end-point's position, velocity, and acceleration during travel between two points $\left(P_{\text {start }}\right.$ and $\left.P_{\text {end }}\right)$ with a limited $V_{\max }$, which is named the set-point-n (SP-n). For SP-1, SP-2, and SP-3, the start positions were (320, $0,0),(1320,0,1000)$, and $(800,-1800,500)$, respectively; the stop positions were $(2600,780,1000),(2500,1200,2000)$, and $(2100,1100,1500)$, respectively, and the $V_{\max }$ was set as 50,60 , and $100 \mathrm{~m} \cdot \mathrm{s}^{-1}$, respectively. The developed algorithm moved the RA between two points, and it could follow the ST-profile in all the three directions. Traveling time in each direction varied because of different distances. The TCP smoothly accelerated in each direction and, after reaching the $V_{\text {max }}$ the velocity remained constant. During deceleration, the TCP smoothly decelerated to stop. The results indicated that the developed motion profile could move the RA with desired acceleration and deceleration profile. 

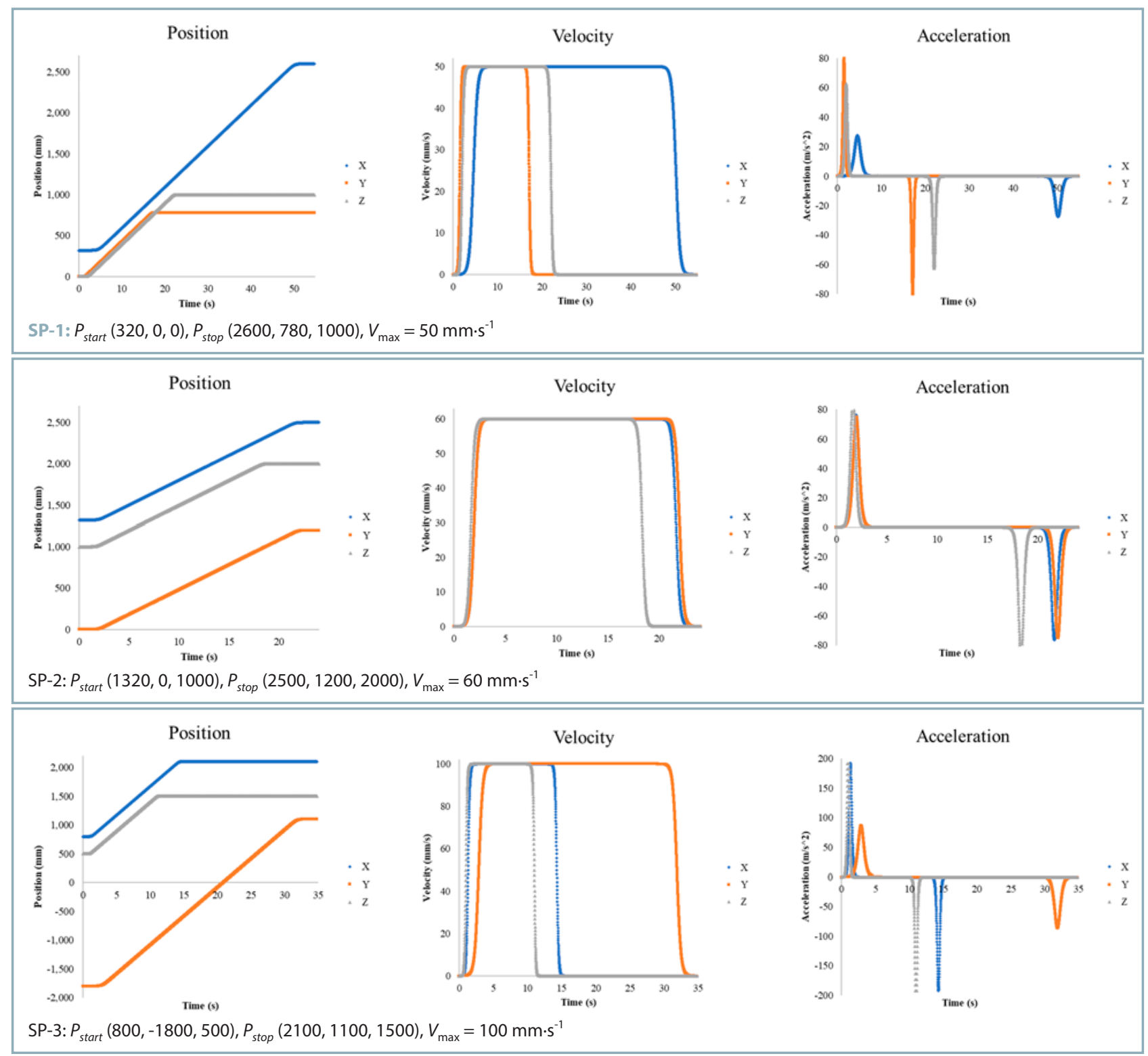

Fig. 6 Motion profile results

\section{PTP motion}

For PTP motion, all joints must start and stop at the same time. Therefore, the total traveling time should be the same for all joints and directions. In this mission, the $V_{\max }$ was not a limitation. As shown in Fig. 7a, b, joints' motion and traveling in three axes were finished in a limited time. In these tests, the traveling time was set as $20 \mathrm{~s}$, which is controllable based on the motion task, and the tool offset was ignored. In each direction, the ST-motion profile was respected. The results showed that the developed algorithm and related equations can move the RA while all joints are able to move in all directions in a predetermined limited time. It can help the system to receive time limitations with a selected related motion plan. The $n$ parameter mentioned in the joint position plot was the number of rotations in $\mathrm{Z}$ screws. This value is controllable when the robotic arm uses a PLC system via analogue code calibrations.

\section{TCP linear motion}

During the TCP linear motion, by setting two positions, the TCP travelled along the shortest path. When this command is triggered, the TCP moves along the shortest path between those two locations and follows ST-profiles. In this test, three SPs were set (Fig. 8). For SP-1, SP-2, and SP-3, the $P_{\text {start }}, P_{\text {stop }}$ and $V_{\max }$ were set as $(320,0,0),(1320,0,1000)$, and (800, $-1800,500) ;(2600,780,1000),(2500,1200,2000)$, and $(2100$, $1100,1500)$; and 50,60 , and $100 \mathrm{~mm} \cdot \mathrm{s}^{-1}$, respectively. As shown in Fig. 8, the RA can manoeuvre along a linear path between STs, indicating that the controlling algorithm was well developed, and it can select the shortest path when necessary. 

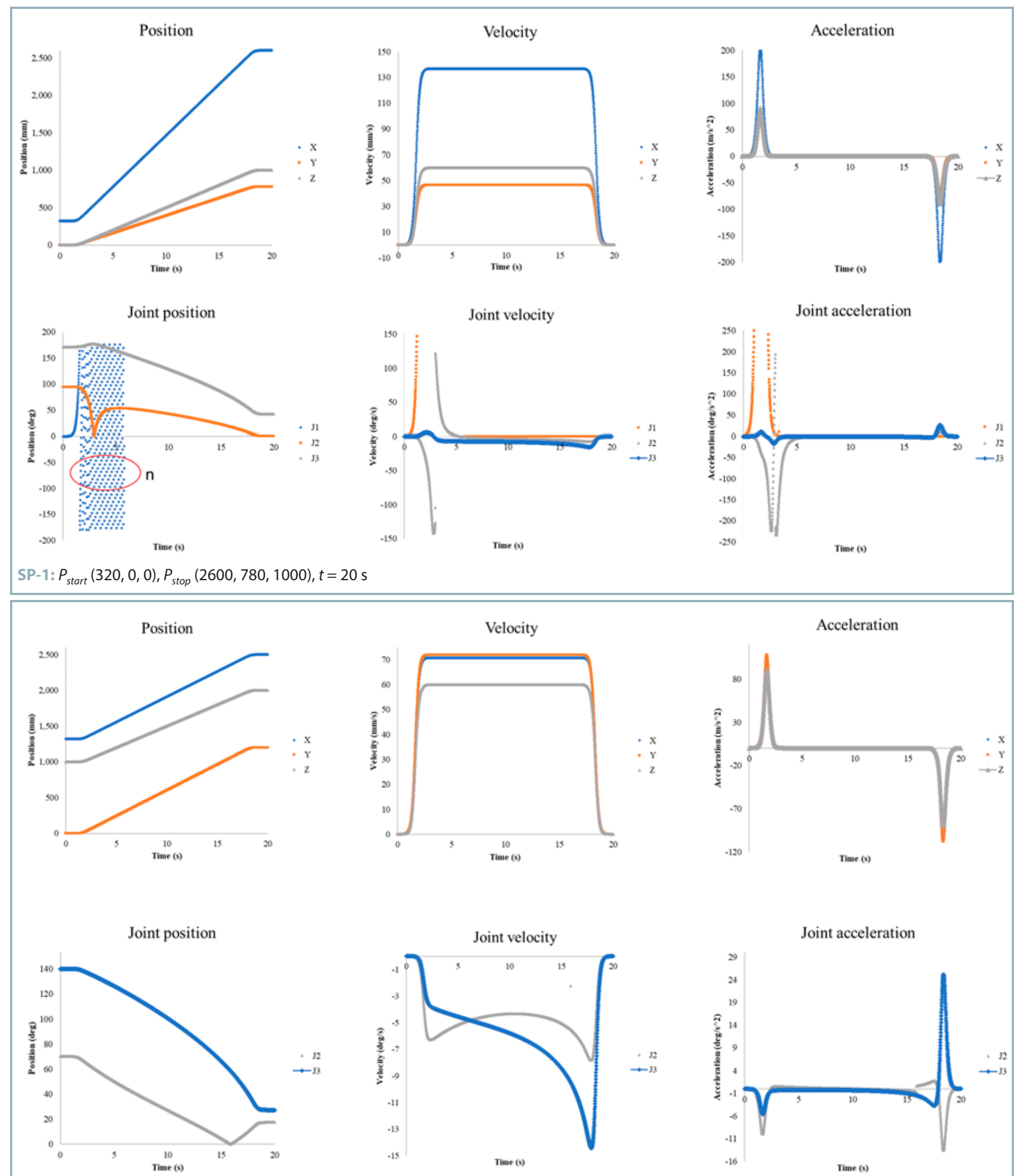

SP-2: $P_{\text {start }}(1320,0,1000), P_{\text {stop }}(2500,1200,2000), t=20 \mathrm{~s}$

Fig. 7a Results of PTP motion 


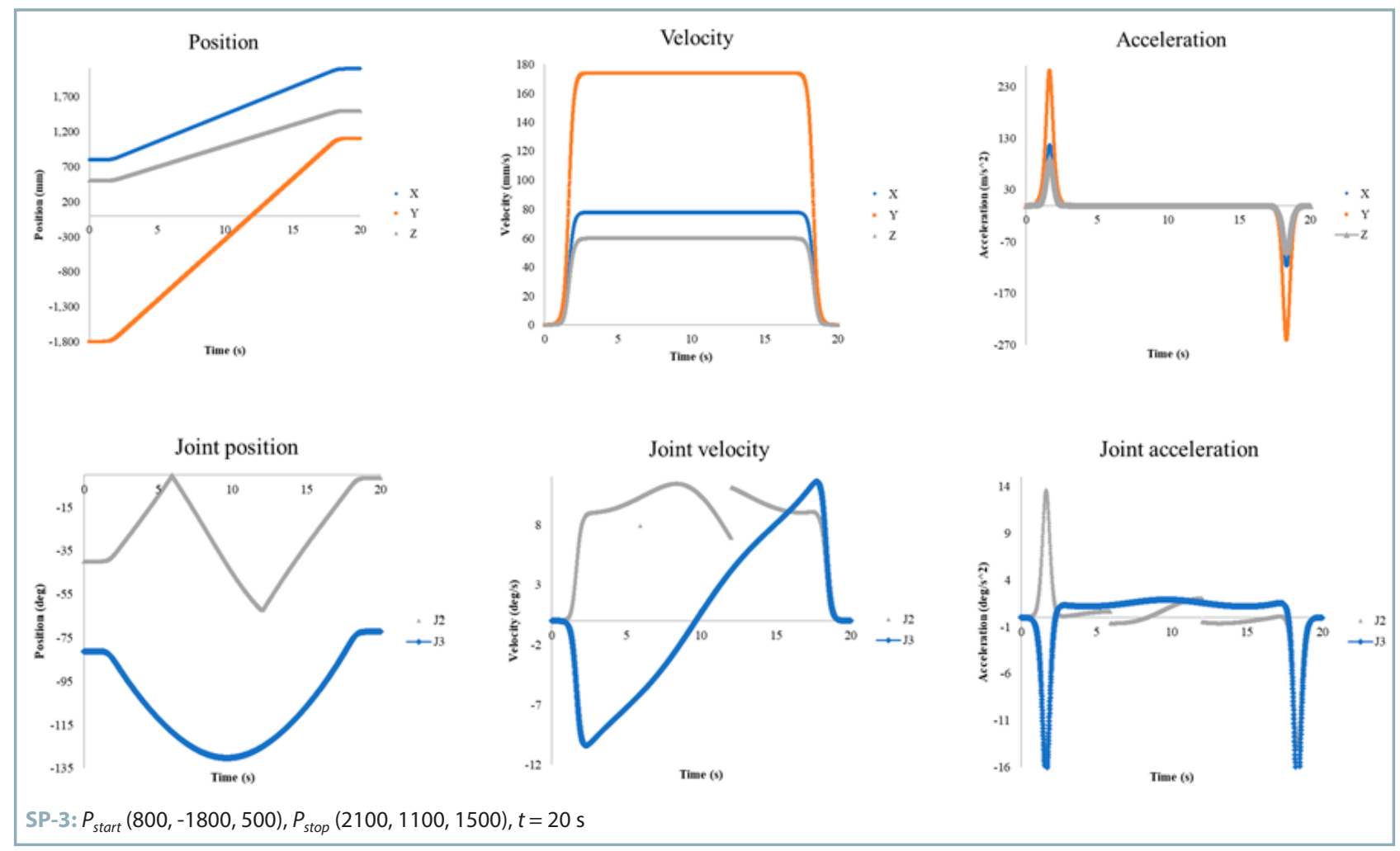

Fig. 7b Results of PTP motion

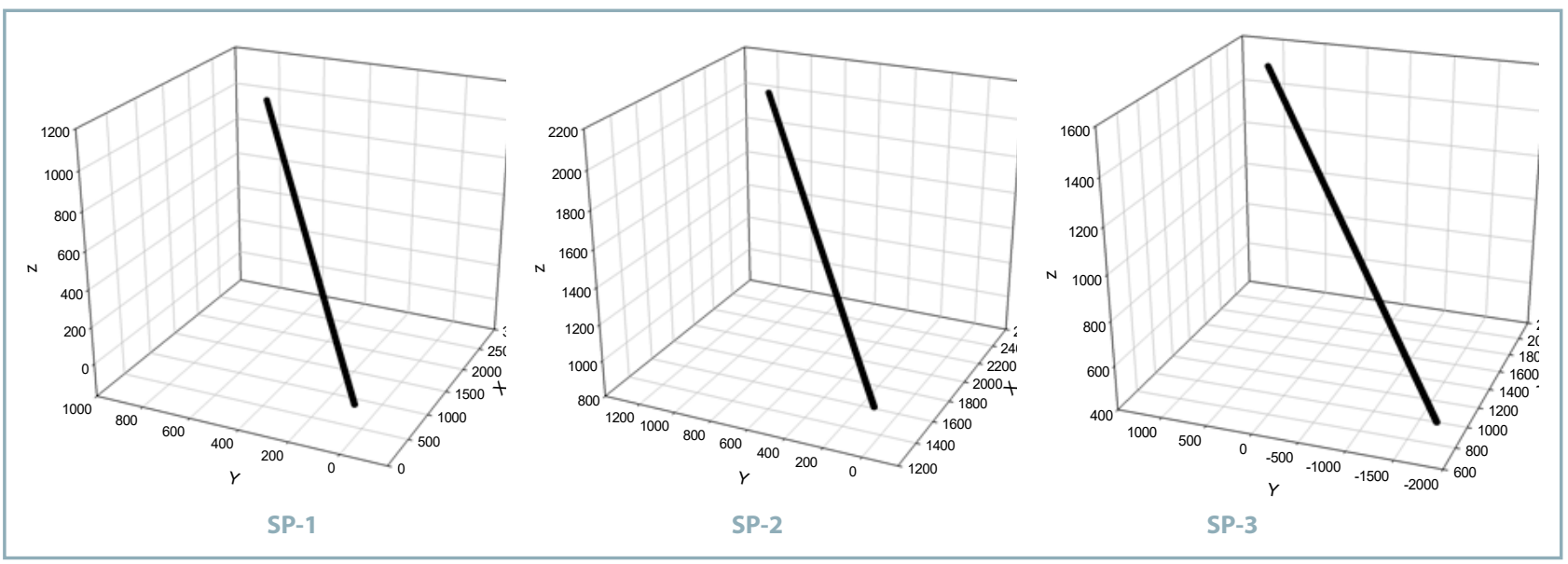

Fig. 8 Results of TCP's linear motion

\section{Spline motion}

Finally, the controlling algorithm could move the RA at a constant height between several points. This test was developed for cases when the RA sprays, fertilizes, monitors, etc. In this regard, three close paths set in different plains and three series of SPs were selected randomly (Table 1). The SP-1, SP-2, and SP-3 were illustrated by blue, yellow, and green colours, respectively. The ST-1, ST-2, and ST-3 were defined to move at 0,500 , and $1500 \mathrm{~mm}$ height on plains in the Z-direction. All points in each SP were inside the workspace. At the same time, TCP's motion had to show a smooth change of velocity and acceleration.
The test results are shown in Fig. 9. Each task was set on a certain plain, suggesting that the algorithm can manoeuvre on a constant Z-value, e. $\mathrm{g}$. if the RA holds an EE with a length of $A \mathrm{~mm}$, the algorithm should be able to consider the $A$ value and care for its damages. For the seeding task, the RA manoeuvres on the ground $(Z=0)$. During spraying, the algorithm considers the average crop height, and the RA carefully moves in order to not damage the plants. 
Table $1 \quad$ Setpoints for spline motion tests

\begin{tabular}{|l||c|c|c|c|c|c|c|c|c|}
\hline \multicolumn{1}{|c|}{} & \multicolumn{3}{|c|}{ SP-1 } & \multicolumn{3}{c|}{ SP-2 } & \multicolumn{2}{c|}{ SP-3 } \\
\cline { 2 - 10 } & $\mathbf{X}$ & $\mathbf{Y}$ & $\mathbf{Z}$ & $\mathbf{X}$ & $\mathbf{Y}$ & $\mathbf{Z}$ & $\mathbf{X}$ & $\mathbf{Y}$ \\
\hline $\mathbf{P 1}$ & 1500 & 600 & 0 & 90 & -1100 & 500 & 140 & 2000 & 1500 \\
\hline P2 & 1500 & -600 & 0 & 300 & -2100 & 500 & 400 & 1000 & 1500 \\
\hline P3 & 2700 & -750 & 0 & 1600 & -2000 & 500 & 1400 & 1000 & 1500 \\
\hline P4 & 2600 & 1000 & 0 & 1400 & -1000 & 500 & 1500 & 2100 & 1500 \\
\hline
\end{tabular}

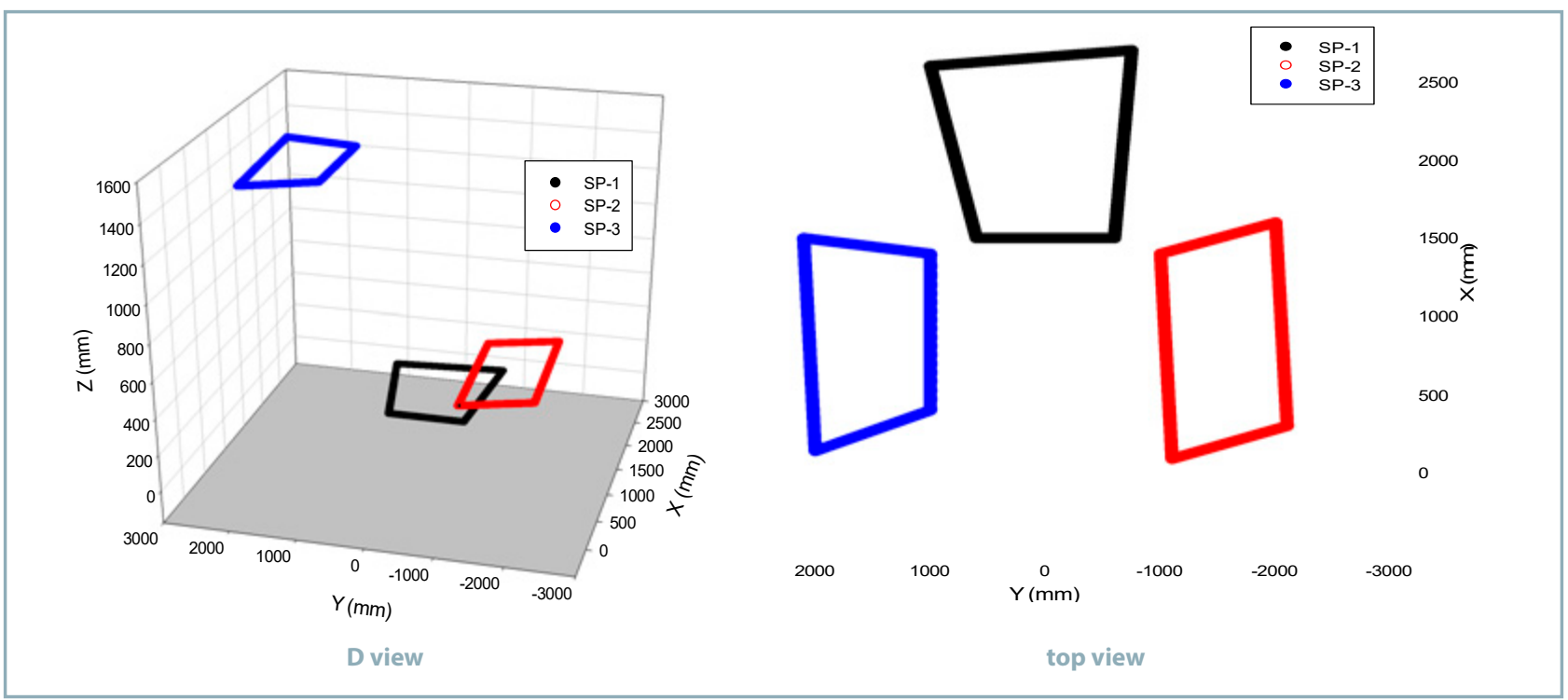

Fig. 9 Results of spline motion tests on three STs

\section{Conclusion}

This paper presented:

1. A 4-DOF SCARA type robotic arm for agriculture applications useable for farm works, such as seeding and planting of various crops using different EEs; farming tasks including minimal cultivation, watering, fertilizing, spraying, and weeding; and performing selection harvesting for various crops.

2. Smooth motion, series of equations based on ST-motion profile to control the acceleration and deceleration of each joint.

3. An algorithm evaluation by PTP motion, TCP linear motion, and spline motion. These motions were developed and evaluated as predicted scenarios for working under field conditions.

4. PTP motion design for cases when the RA harvests or waters the crops.

5. The TCP motion design to move along the shortest path in a limited time or performing high-speed tasks.

6. Spline motion design for cases when the RA moves on a predetermined path.

\section{References}

ALIASGARIAN, S. - GHASSEMZADEH, H. R. - MOGHADDAM, M. - GHAFFARI, H. 2015. Mechanical damage of strawberry during harvest and postharvest operations. In Acta Technologica Agriculturae, vol. 18, no. 1, pp. 1-5.

AYRE, M. - MC COLLUM, V. - WATERS, W. - SAMSON, P. - CURRO, A. - NETTLE, R. - PASCHEN, J. A. - KING, B. - REICHELT, N. 2019. Supporting and practising digital innovation with advisers in smart farming. In NJAS - Wageningen Journal of Life Sciences, vol. 90-91, article no. 100302.

BRAVI, L. - MURMURA, F. - SAVELLI, E. - VIGANÒ, E. 2019. Motivations and actions to prevent food waste among young italian consumers. In Sustainability, vol. 11, no. 4, article no. 1110.

CVIKLOVIČ, V. - OLEJÁR, M. - HRUBÝ, D. - PALKOVÁ, Z. - LUKÁČ, O. HLAVÁČ, P. 2016. Navigation algorithm using fuzzy control method in mobile robotics. In Acta Technologica Agriculturae, vol. 19, no. 1, pp. 19-23.

FAO. 2017. The future of food and agriculture - Trends and challenges. Rome : FAO, 163 pp. ISBN 9789251095515.

GARNER, J. P. - MEEHAN, C. L. - FAMULA, T. R. - MENCH, J. A. 2006. Genetic, environmental, and neighbor effects on the severity of stereotypies and feather picking in Orange-winged Amazon parrots (Amazona amazonica): An epidemiological study. In Applied Animal Behaviour Science, vol. 96, no. 1-2, pp. 153-168.

KAMATA, T. - ROSHANIANFARD, A. - NOGUCHI, N. 2018. Heavyweight crop harvesting robot - controlling algorithm. In IFACPapersOnLine, vol. 51, no. 17, pp. 244-249. 
KASHKAROV, A. - DIORDIIEV, V. - SABO, A. - NOVIKOV, G. 2018. Semi-autonomous drone for agriculture on the tractor base. In Acta Technologica Agriculturae, vol. 21, no. 4, pp. 149-152.

KHOSRO ANJOM, F. K. - VOUGIOUKAS, S. G. 2019. Online prediction of tray-transport request time using mechanistic grey box models for improved scheduling of robotic strawberry harvest-aids. In Biosystems Engineering, vol. 188, pp. 265-287.

KLERKX, L. - JAKKU, E. - LABARTHE, P. 2019. A review of social science on digital agriculture, smart farming and agriculture 4.0: New contributions and a future research agenda. In NJAS Wageningen Journal of Life Sciences, vol. 90-91, article no. 100315. LI, Z. - MIAO, F. - YANG, Z. - WANG, H. 2019. An anthropometric study for the anthropomorphic design of tomato-harvesting robots. In Computers and Electronics in Agriculture, vol. 163, article no. 104881.

LIU, Y. - NOGUCHI, N. - ROSHANIANFARD, A. 2017. Simulation and test of an agricultural unmanned airboat maneuverability model. In International Journal of Agriculture and Biological Engineering, vol. 10, no. 1, pp. 88-96.

LUO, L. - TANG, Y. - LU, Q. - CHEN, X. - ZHANG, P. - ZOU, X. 2018 $A$ vision methodology for harvesting robot to detect cutting points on peduncles of double overlapping grape clusters in a vineyard. In Computers in Industry, vol. 99, pp. 130-139.

LV, J. - WANG, Y. - XU, L. - GU, Y. - ZOU, L. - YANG, B. - MA, Z. 2019. A method to obtain the near-large fruit from apple image in orchard for single-arm apple harvesting robot. In Scientia Horticulturae, vol. 257, article no. 108758.

MARINOUDI, V. - SØRENSEN, C. G. - PEARSON, S. - BOCHTIS, D. 2019. Robotics and labour in agriculture. A context consideration. In Biosystems Engineering, vol. 184, pp. 111-121.

ROSHANIANFARD, A. 2018. Development of a Harvesting Robot for Heavy-Weight Crop. PhD thesis, Hokkaido University.

ROSHANIANFARD, A. - KAMATA, T. - NOGUCHI, N. 2018. Performance evaluation of harvesting robot for heavy-weight crops. In IFAC-PapersOnLine, vol. 51, no. 17, pp. 332-338.

ROSHANIANFARD, A. - MENGMENG, D. - NEMATOLLAHZADEH, S. 2021. A 4-DOF SCARA robotic arm for various farm applications: Designing, kinematic modelling, and parameterization. In Acta Technologica Agriculturae, vol. 24, no. 2, pp. 61-66.
ROSHANIANFARD, A. - NOGUCHI, N. 2016. Development of a 5DOF robotic arm (RAVebots-1) applied to heavy products harvesting. In IFAC-PapersOnLine, vol. 49, no. 16, pp. 155-160.

ROSHANIANFARD, A. - NOGUCHI, N. 2017. Development of heavy-weight crops robotic harvesting system (HCRHS). The $3^{\text {rd }}$ International Conference on Control, Automation and Robotics (ICCAR 2017). Tokyo, Japan.

ROSHANIANFARD, A. - NOGUCHI, N. 2018a. Characterization of pumpkin for a harvesting robot. In IFAC-PapersOnLine, vol. 51, no. 17, pp. 23-30.

ROSHANIANFARD, A. - NOGUCHI, N. 2018b. Kinematics analysis and simulation of a 5DOF articulated robotic arm applied to heavy products harvesting. In Tarim Bilimleri Dergisi, vol. 24, no. 1, pp. 90-104.

ROSHANIANFARD, A. - NOGUCHI, N. - OKAMOTO, H. - ISHII, K. 2020 A review of autonomous agricultural vehicles (The experience of Hokkaido University). In Journal of Terramechanics, vol. 91, pp. 155-183.

SHIBUSAWA, S. 2018. Digital farming approach changes the context. In IFAC-PapersOnLine, vol. 51, no. 17, pp. 67-69.

SINGH, R. - SINGH, G. S. 2017. Traditional agriculture: a climatesmart approach for sustainable food production. In Energy, Ecology and Environment, vol. 2, no. 5, pp. 296-316.

WANG, H. - NOGUCHI, N. 2019. Navigation of a robot tractor using the centimeter level augmentation information via Quasi-Zenith Satellite System. In Engineering in Agriculture, Environment and Food, vol. 12, no. 4, pp. 414-419.

WILLIAMS, H. A. M. - JONES, M. H. - NEJATI, M. - SEABRIGHT, M. J. BELL, J. - PENHALL, N. D. - BARNETT, J. J. - DUKE, M. D. - SCARFE, A. J. - AHN, H. S. - LIM, J. - MACDONALD, B. A. 2019. Robotic kiwifruit harvesting using machine vision, convolutional neural networks, and robotic arms. In Biosystems Engineering, vol. 181, pp. 140-156. ZHANG, Z. - NOGUCHI, N. - ISHII, K. - YANG, L. - ZHANG, C. 2013. Development of a robot combine harvester for wheat and paddy harvesting. In IFAC Proceedings Volumes, vol. 46, no. 4, pp. 45-48. 